\title{
Increased survival and proliferation of the epidemic strain Mycobacterium abscessus subsp. massiliense CRM0019 in alveolar epithelial cells
}

Giovanni Monteiro Ribeiro ${ }^{1}$, Cristianne Kayoko Matsumoto ${ }^{1}$, Fernando Real ${ }^{1,2}$, Daniela Teixeira', Rafael Silva Duarte ${ }^{3}$, Renato Arruda Mortara', Sylvia Cardoso Leão ${ }^{1}$ and Cristiane de Souza Carvalho-Wodarz ${ }^{1,4^{*}}$ (D)

\begin{abstract}
Background: Outbreaks of infections caused by rapidly growing mycobacteria have been reported worldwide generally associated with medical procedures. Mycobacterium abscessus subsp. massiliense CRM0019 was obtained during an epidemic of postsurgical infections and was characterized by increased persistence in vivo. To better understand the successful survival strategies of this microorganism, we evaluated its infectivity and proliferation in macrophages (RAW and BMDM) and alveolar epithelial cells (A549). For that, we assessed the following parameters, for both M. abscessus CRM0019 as well as the reference strain M. abscessus ATCC 19977: internalization, intracellular survival for up 3 days, competence to subvert lysosome fusion and the intracellular survival after cell reinfection.

Results: CRM0019 and ATCC 19977 strains showed the same internalization rate (approximately 30\% after $6 \mathrm{~h}$ infection), in both A549 and RAW cells. However, colony forming units data showed that CRM0019 survived better in A549 cells than the ATCC 19977 strain. Phagosomal characteristics of CRM0019 showed the bacteria inside tight phagosomes in A549 cells, contrasting to the loosely phagosomal membrane in macrophages. This observation holds for the ATCC 19977 strain in both cell types. The competence to subvert lysosome fusion was assessed by acidification and acquisition of lysosomal protein. For M. abscessus strains the phagosomes were acidified in all cell lines; nevertheless, the acquisition of lysosomal protein was reduced by CRM0019 compared to the ATCC 19977 strain, in A549 cells. Conversely, in macrophages, both M. abscessus strains were located in mature phagosomes, however without bacterial death. Once recovered from macrophages M. abscessus could establish a new intracellular infection. Nevertheless, only CRM0019 showed a higher growth rate in A549, increasing nearly 10-fold after 48 and 72 h.

Conclusion: M. abscessus CRM0019 creates a protective and replicative niche in alveolar epithelial cells mainly by avoiding phagosome maturation. Once recovered from infected macrophages, CRM0019 remains infective and displays greater intracellular growth in A549 cells compared to the ATCC 19977 strain. This evasion strategy in alveolar epithelial cells may contribute to the long survival of the CRM0019 strain in the host and thus to the inefficacy of in vivo treatment.
\end{abstract}

Keywords: Mycobacterium abscessus, Phagosome, Acidification, A549, Macrophages, CRM0019

\footnotetext{
* Correspondence: cristiane.carvalho@helmholtz-hzi.de

'Departamento de Microbiologia, Imunologia e Parasitologia, Escola Paulista

de Medicina, Universidade Federal de São Paulo, São Paulo, SP, Brazil

${ }^{4}$ Department of Drug Delivery, Helmholtz Institute for Pharmaceutical

Research Saarland (HIPS), Helmholtz Centre for Infection Research (HZI),

Saarbrücken, Germany

Full list of author information is available at the end of the article
} 


\section{Background}

Mycobacterium abscessus is a nontuberculous mycobacterium (NTM) widely distributed in the environment. This bacterium is responsible for lung diseases [1,2] and healthcare-associated extrapulmonary infections [3-5]. M. abscessus is indeed the major pulmonary pathogen within the rapid-growing mycobacteria (RGM) group [2], and it has been the most frequent NTM found in the lungs of cystic fibrosis (CF) patients [6-8].

As for other NTM, M. abscessus is present in environmental reservoirs (e.g. water and soil) and has been recently isolated from drinking water [9-11]. The acquisition of this bacterium is therefore most likely to occur from the environment, rather than via person-toperson transmission [12]. Despite sharing genes typically found in environmental organisms [13], M. abscessus also harbors genes characteristic of pathogenic bacteria $[14,15]$. Likewise, it is an intracellular pathogen of macrophages and free-living amoebas $[16,17]$.

M. abscessus has been classified into three subspecies that are officially accepted: $M$. abscessus subsp. abscessus, $M$. abscessus subsp. massiliense and M. abscessus subsp. bolletii [18]. These subspecies cause similar diseases but can be differentiated by PCR-restriction enzyme analysis (PRA) of the hsp65 gene, rpoB gene sequencing and polymorphisms in the erm gene [19]. $M$. abscessus pathogenicity is closely related to its colony morphology on an agar plate: organisms without glycopeptidolipids (GPLs) on their surface show a rough (R) colony morphology, while those with GPLs display a smooth (S) morphology [16, 20-22]. The $S$ variant is motile, biofilm-forming, and less virulent [16, 21, 23]. By contrast, the $\mathrm{R}$ variant is non-motile, but more virulent than the $S$ variant [16]. In the lung, M. abscessus infection appears to be associated with the $\mathrm{R}$ variant, which has a highly persistent behavior [16, 24, 25]. Even so, both morphotypes $\mathrm{R}$ and $\mathrm{S}$ can be isolated from clinical samples [23, 26, 27], and an interchange between these forms may possibly occur [16, 21]. The clinical isolate M. abscessus subsp. massiliense CRM0019 was obtained during an epidemic of postsurgical infections related to laparoscopic, arthroscopic and plastic surgeries in 2006, in Rio de Janeiro city, Brazil [28-30] and showed a smooth morphotype upon isolation ("personal communication” by Dr. Rafael Duarte). This isolate belongs to a strain that affected more than 2000 patients between 2004 and 2008 [29, 30], and has substantial tolerance to high concentrations of glutaraldehyde [31].

The numerous cases of $M$. abscessus infection related to a single clone reported in Brazil raised questions about the transmission of this bacterium and its survival in the host. From these questions, studies have mostly been conducted regarding bacterial survival. CRM0019 has increased persistence in vivo [32], which can be attributed to the capacity of $M$. abscessus to manipulate host immune responses in macrophages, epithelial cells, endothelial cells and neutrophils [33-38]. Nonetheless, little is known about the interaction of the CRM0019 isolate with lysosomes or its capacity for reinfection. This is an essential question to address in order to understand the successful intracellular survival of pathogenic mycobacteria, classically represented by $M$. tuberculosis, which arrests progression of phagosome maturation [39, 40]. Macrophages often fail to kill pathogenic mycobacteria, resulting in survival and proliferation of the bacilli [41-43] as observed for other NTM [44, 45] including the CRM0019 isolate [32].

Besides macrophages, the respiratory epithelium plays an important role in defending against respiratory pathogens [46]. There is evidence that epithelial cells can act as a replicative niche for Mycobacterium [47-52]. Even so, their contribution to the pathogenicity in humans is not as yet clear. A recent study using a human ex vivo lung tissue culture model reinforced the evidence for mycobacteria infection in alveolar epithelial cells (AEC) [53]. A549 is a human type II carcinoma cell line established as a model of type II AEC [54, 55]. As such, this cell line has been extensively used to study lung infections with a range of pathogens [56-58] including mycobacteria [49, 50, 59, 60]. Besides being shielded from phagocytic cells, mycobacteria inside AEC could acquire a more infective phenotype. Indeed, it has been shown that passage of mycobacteria through alveolar epithelial cells promotes the conversion of non-virulent $M$. smegmatis to a virulent phenotype before they infect macrophages [61]. Likewise, a recent study also showed that M. abscessus obtained from amoeba are more infective than those growing extracellularly [62].

Understanding the survival mechanisms engaged by M. abscessus CRM0019 in cells other than macrophages may shed light on important aspects of its intracellular behavior that could play a role in its in vivo persistence and virulence. We investigated herein the intracellular survival of $M$. abscessus CRM0019 in comparison to reference strain $M$. abscessus ATCC 19977 in both A549 epithelial cells and macrophages, by addressing the interaction with lysosomes and reinfection capability.

\section{Methods \\ Cell cultures}

The cell lines A549 - type II alveolar epithelial cell line (DSMZ GmbH, Braunschweig, Germany) and RAW 264.7 - mouse leukemic monocyte macrophage cell line (ATCC, Manassas VA, USA) were maintained respectively in DMEM and RPMI medium (Sigma Chemical Co., St Louis, MO.), both supplemented with 10\% FBS (Life Technologies, Grand Island, NY, USA), $100 \mu \mathrm{g} / \mathrm{ml}$ streptomycin and $100 \mathrm{U} / \mathrm{ml}$ penicillin (Sigma). Cells 
were grown in T75 flasks in $5 \% \mathrm{CO}_{2}$, at $37{ }^{\circ} \mathrm{C}$. Cultures were trypsinized upon reaching approximately $75 \%$ confluence, and concentrated by centrifugation at $360 \times g$ at $25{ }^{\circ} \mathrm{C}$ for $10 \mathrm{~min}$. Cells were counted in a Neubauer chamber and viability assessed by trypan blue exclusion. Bone marrow-derived macrophages (BMDM) were obtained and cultivated as previously described [63] and used after 6-7 days of differentiation.

\section{Bacterial cultures}

M. abscessus subsp. massiliense CRM0019 was isolated from a postsurgical wound during the 2006-2007 epidemic in Rio de Janeiro, Brazil [28]. M. abscessus subsp. abscessus smooth variant was isolated from the sputum of CF patients [27], and kindly provided by Prof. Dr. John Perry, Newcastle University. The reference strain M. abscessus subsp. abscessus ATCC 19977 was used in parallel. Both bacteria, ATCC 19977 and CRM0019, were transformed with the Escherichia colimycobacterium expression vector pMV262 containing the green fluorescent protein (GFP) gene (pMV262-gfp). In some experiments, $M$. smegmatis $\mathrm{mc}^{2} 155$, wild type or transformed with the same plasmid, was used. All mycobacterial strains were grown in Middlebrook 7H9 liquid medium (Becton Dickinson, Franklin Lakes, NJ), supplemented with oleic acid, albumin, dextrose and catalase (OADC - Becton Dickinson), 0.5\% glycerol and $0.05 \%$ Tween 80 at $37{ }^{\circ} \mathrm{C}$, for $72 \mathrm{~h}$. Transformed bacteria were grown in medium containing kanamycin $(50 \mu \mathrm{g} / \mathrm{ml})$ and sub-cultured in fresh medium for $24 \mathrm{~h}$ before the experiments.

\section{Mycobacteria-cells infection}

A549 cells and macrophages $\left(5 \times 10^{4}\right.$ per well) previously grown in 24-well plates in medium without antibiotics were infected simultaneously with single-cell bacterial suspensions. Accordingly, bacterial cells in exponential growth phase were pelleted, washed in PBS and suspended in DMEM. Clumps of bacteria were removed by passing through a syringe needle ( 25 gauge), followed by an ultrasonic water bath for $15 \mathrm{~min}$ and low-speed centrifugation $(120 \times g)$ for $2 \mathrm{~min}$. The optical densities of bacterial suspensions were adjusted to a multiplicity of infection (MOI) of 10 or 100 , according to the experiment. MOI of 10 was used for macrophages and MOI of 100 for A549 cells. The experiments with M. smegmatis followed the same protocols as used for $M$. abscessus.

After $6 \mathrm{~h}$ uptake, the cells were washed with PBS to remove extracellular bacteria. Thereafter cells were incubated with DMEM containing $30 \mu \mathrm{g} / \mathrm{ml}$ amikacin (Sigma) to avoid extracellular bacteria growth [16]. Infected cultures were further incubated for 6, 24, 48 and $72 \mathrm{~h}$ at $37{ }^{\circ} \mathrm{C}$, in $5 \% \mathrm{CO}_{2}$.

\section{Colony-forming unit assay}

Infected macrophages and A549 cells were washed with PBS and lysed with sterilized water. Quantitative cultures for mycobacteria were performed using 10fold serial dilutions in PBS/0.05\% Tween 80 inoculated on LB agar plates. Subsequently, $20 \mu \mathrm{l}$ were plated in triplicate with serial dilutions. The plates were incubated at $37{ }^{\circ} \mathrm{C}$ and the colonies counted after 3 or 4 days. Results were expressed in terms of colonyforming units (CFU) per milliliter.

To verify the infectivity competence of mycobacteria in reinfection assays, mycobacteria were obtained from BMDM previously infected for $24 \mathrm{~h}$. Macrophages were lysed and bacterial suspensions frozen at $-20{ }^{\circ} \mathrm{C}$ with $10 \%$ glycerol. Before use in experiments, bacteria were grown in $7 \mathrm{H} 9$ liquid fresh medium for $72 \mathrm{~h}$ and prepared for cell infection as described above.

\section{Fluorescence microscopy}

For lysosome-staining assays, A549 cells and macrophages were fixed with 3\% paraformaldehyde (PFA) in PBS for $15 \mathrm{~min}$ at room temperature and quenched for 15 min with $50 \mathrm{mM}$ glycine in PBS. Preceding immunostaining, cells were permeabilized with $0.1 \%$ saponin solution and $1 \%$ bovine serum albumin (BSA - Sigma) in PBS, for $15 \mathrm{~min}$ at room temperature. For A549 cells, mouse $\alpha$-human and for RAW cells rabbit $\alpha$ mouse LAMP- 1 and $\alpha$-cathepsin D antibodies (supernatants from DSHB, Iowa University, USA) were used at 1:10 dilution for $1 \mathrm{~h}$. The corresponding fluorescent secondary antibodies, $\alpha$-mouse-IgG for A549 cells and $\alpha$-rabbit-IgG for RAW cells (AlexaFluor), were used at a dilution of 1:250 for $1 \mathrm{~h}$ at room temperature. Alternatively, live adherent cells were infected as described before and incubated with medium containing $200 \mathrm{nM}$ LysoTracker Red DND-99 (Molecular Probes, Thermo Scientific) for $1 \mathrm{~h}$ at $37{ }^{\circ} \mathrm{C}$, to evaluate phagosomal acidification. Afterwards, cells were washed with HBSS (Sigma) and coverslips were fixed with 4\% PFA for 15 min.

Nuclear staining was performed using $5 \mathrm{nM} \mathrm{4,6'-dia-}$ midino-2-phenylindole (DAPI, Invitrogen, Thermo Scientific). After staining, the coverslips were mounted on slides using aqueous mounting medium (Dako Cytomation, Denmark). Samples were analyzed by epifluorescence microscopy using a Zeiss Axiovert Fluorescence microscope (Zeiss, Germany) or Leica SP5 II TS confocal microscope (Leica Microsystems, Germany) microscope. Microscopic images of fixed samples were acquired at $1024 \times 1024$ resolution, using a $100 \times$ (HCX PL APO 100×/1.44 CORR CS) oil immersion objective and $\mathrm{z}$-stacks with steps ranging from 0.3 to $0.5 \mu \mathrm{m}$. 


\section{Live cell images}

Live imaging was performed by serial acquisition of images from live A549 cells pre-loaded with LysoTracker Red (200 nM) and infected with $M$. abscessus ATCC 19977 or M. smegmatis mc $^{2} 155$ for up to 36 h. The cells were placed in microincubators coupled to the confocal system. Images were taken every $15 \mathrm{~min}$. Lasers were adjusted to no more than $5 \%$ of potency at resonant scanning mode $(4000 \mathrm{~Hz})$ to minimize phototoxicity. Multichamber Hi-Q4 dishes (Ibidi $\mathrm{GmbH}$ ) were employed for experiments in which two different cell cultures, infected with different mycobacteria, were imaged in the same live imaging session. Different microscopic fields could be imaged for each condition using the multiposition tool of the confocal system.

Confocal images were analyzed with Imaris v.7.4.2 software (Bitplane AG, Andor Technology). The software allowed the construction of isosurfaces based on GFP signaling of the bacteria [64] that retrieves different morphological parameters such as bacterial volume, area and fluorescence intensity. These isosurfaces represent the region where the GFP signal of the bacteria is located in multidimensional images; they could be used to recover the fluorescence intensity of the Lysotracker Red DND-99 probe that represents the acquisition of this lysosomal probe in the bacteria-containing phagosome. Thus, the relative fluorescence intensity of LysoTracker Red detected by GFP-constructed bacterial isosurfaces is an inference of phagosomal acidification that could be measured dynamically in live cell imaging.

\section{Flow cytometry}

A549 and RAW cells grown in 24-well plates, noninfected or infected with wild-type or GFP-expressing strains (CRM0019 or ATCC 19977) as described before were trypsinized after $6,24,48$ and $72 \mathrm{~h}$ of infection and collected with $1 \mathrm{ml}$ of DMEM containing 10\% FBS. Cells were then centrifuged at $860 \times g$ for $10 \mathrm{~min}$ at room temperature, washed with PBS, and fixed with $4 \%$ PFA for $20 \mathrm{~min}$ at room temperature. After one additional PBS washing, the samples were resuspended in $500 \mu \mathrm{l}$ of PBS with $10 \%$ FBS at $4{ }^{\circ} \mathrm{C}$ and immediately analyzed in a FACSCalibur flow cytometer (Becton Dickinson, San Jose, CA).

Intracellular infection was evaluated with FlowJo software (version 9.7.6, Tree Star, San Carlos, CA). For this, cells infected with wild-type $M$. abscessus or not were used as control groups. At each evaluated time, the positive fluorescent region was defined on the basis of control samples, which were GFP-negative, determining the percentage of infected cells (GFP-positive cells). The infection efficacy was determined as the fluorescence intensity of GFP-positive cells minus negative control values, and the mean fluorescence intensity (MFI) was calculated, using geometric mean value. The progression of infection by different strains over time was analyzed by comparing the fluorescence ratio, which was calculated for each time point as $\left(\mathrm{GFP}^{+} \mathrm{MFI}\right) /\left(\mathrm{GFP}^{+} \mathrm{MFI}+\mathrm{GFP}^{-}\right.$ MFI).

\section{Transmission electron microscopy}

Macrophages or A549 cells were grown in $75 \mathrm{~cm}^{2}$ flasks and infected with $M$. abscessus, clinical or reference strain, as described before. The cultures were washed with PBS and fixed with a solution containing $2.5 \%$ glutaraldehyde, $2 \%$ formaldehyde, $5 \mathrm{mM} \mathrm{CaCl}_{2}$ and $5 \%$ sucrose in $0.1 \mathrm{M}$ sodium cacodylate buffer, $\mathrm{pH} 7.2$, for $1 \mathrm{~h}$ at room temperature. Samples were post-fixed in $0.1 \mathrm{M}$ sodium cacodylate buffer, $\mathrm{pH} 7.2$ containing $0.8 \%$ osmium tetroxide and $2 \%$ potassium ferricyanide for $1 \mathrm{~h}$, followed by dehydration with a graded series of acetone (70, 90 and 100\%) and propylene oxide for $10 \mathrm{~min}$ each at room temperature. Afterwards, the cells were embedded in epoxy resin. Ultrathin sections (50-60 nm) were cut with a diamond knife, collected onto Butvar-coated copper grids, post-stained with $2 \%$ uranyl acetate (3 min) and lead citrate (1 min) and observed with a transmission electron microscope (Jeol 1200EX) at an accelerating voltage of $80 \mathrm{kV}$.

\section{Methyl-thiazolyl tetrazolium (MTT) reduction assay}

Cells were seeded in 96-well plates in triplicate at a density of $1 \times 10^{5}$ cells per well $24 \mathrm{~h}$ before infection. Thereafter, cells were infected for 6-72 $\mathrm{h}$ as described before and the viability checked with MTT (Sigma), following the manufacturer's instructions. The plates were read at $540 \mathrm{~nm}$ using a plate reader (Multiskan MS, Labsystem).

\section{Statistical analysis}

All data were recorded as mean $\pm \mathrm{SD}$, from 2 or 3 independent experiments, as indicated in the respective figure captions. Statistical analysis was performed using the software package Prism6 ${ }^{\circ}$ (GraphPad Prism, San Diego, CA, USA). Significance was determined by t-test or twoway ANOVA, with Bonferroni posttest. Differences were considered statistically significant at $p<0.05$.

\section{Results}

Comparative internalization and survival of $M$. abscessus strains

To evaluate $M$. abscessus infection and survival in epithelial cells (A549) and macrophages (RAW and BMDM), the clinical strain M. abscessus CRM0019 and the reference strain $M$. abscessus ATCC 19977 were used to infect cells for 6 to $72 \mathrm{~h}$. Infected cells were fixed and analyzed by flow cytometry. The percentage of infected cells (GFP-positive cells) was determined for A549 and RAW cells (Fig. 1a, b). The internalization rate of both 


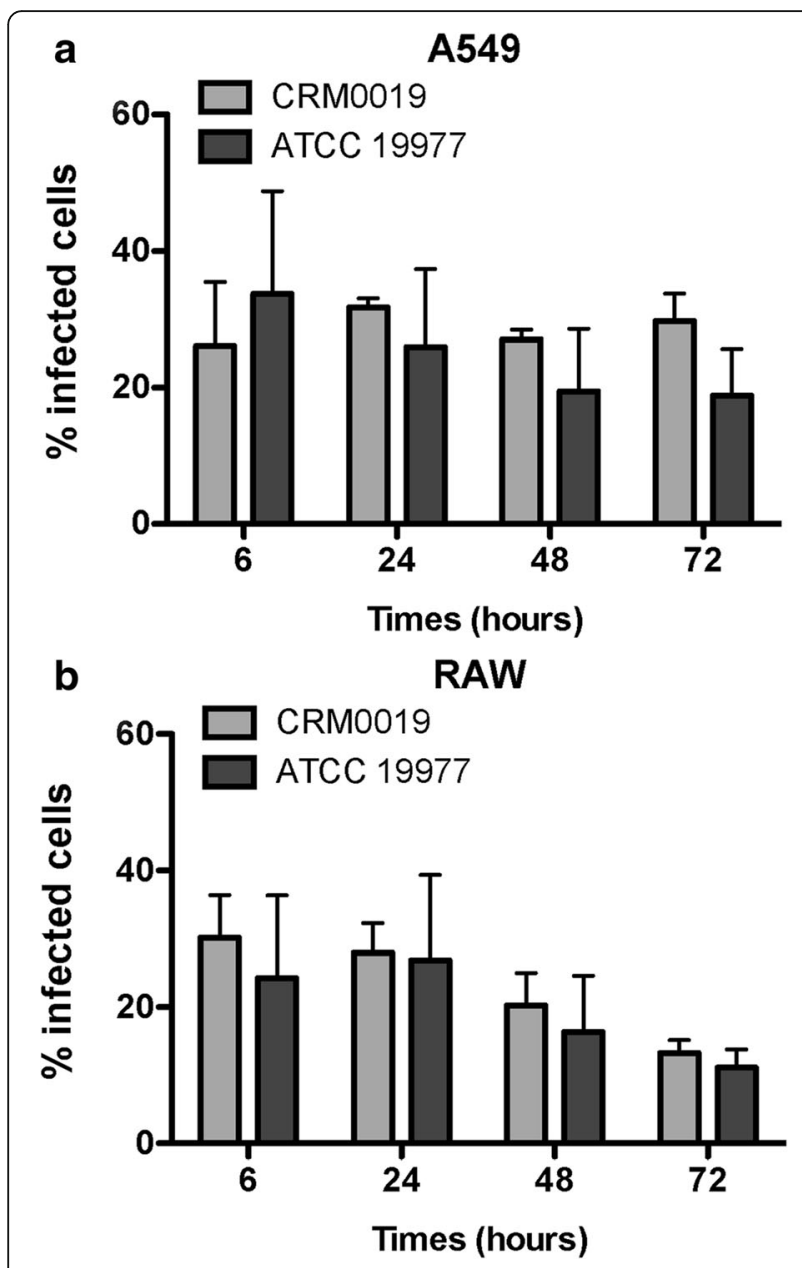

Fig. 1 Internalization rate of Mycobacterium abscessus CRM0019 and Mycobacterium abscessus ATCC 19977. a and b Percentage of infected cells determined by flow cytometry, for both A549 (a) and RAW (b) cells. No significant difference was observed between the strains at each time point. Data represent mean +/- SD from 3 independents experiments

strains was similar in both cell lines, with approximately $30 \%$ infection after $6 \mathrm{~h}$. However, for RAW cells the proportion of infected cells decreased after $72 \mathrm{~h}$, to $15 \%$ in the case of both strains. Such a reduction in the percentage of infected cells is most likely due to the proliferation of uninfected cells in the same culture, as the infection itself did not induce cell death (see Additional file 1). For primary macrophages (BMDM) a similar reduction in the cell viability was observed, in both infected and uninfected cultures (see Additional file $1 \mathrm{C}$ ). These results are not unexpected, since primary cells are usually characterized as having a short life span.

Intracellular bacterial survival was determined by CFU counting of viable bacilli over a period of $72 \mathrm{~h}$. Despite the similar infection rate in A549 cells, CRM0019 showed higher survival and proliferative capability compared to the ATCC 19977 strain, resulting in sustained infection after $24 \mathrm{~h}$ (Fig. 2a). Similar behavior in A549 cells was observed for another clinical strain of M. abscessus, also with $\mathrm{S}$ morphotype, and recently isolated from sputum of CF patients. The efficient survival in A549 cells could also be observed in cultures without amikacin, in which, as expected, more colonies were obtained compared to the untreated culture (see Additional file 2). For both, RAW and BMDM macrophages, a similar intracellular survival of CRM0019 and ATCC 19977 strains was seen Fig. 2 b, c).

The growth rate of the two bacterial strains was determined (see Additional file 3) by calculating the ratio between CFU obtained at $6 \mathrm{~h}(\mathrm{Ti})$ and the additional time points (Tf), i.e., 24,48 and 72 h. The clinical strain showed approximately 20 -fold increase in the number of intracellular bacilli in A549 cells, while the reference strain showed an increase of approximately 5 -fold. In macrophages, both strains showed the same growth rate over time, which is in line with the CFU counts obtained in Fig. 2 b, c. Despite being highly infective, M. abscessus did not induce host cell death during the experimental period (see Additional file 1).

Intracellular proliferation of $M$. abscessus was also confirmed by flow cytometry (Fig. 3). The growth was evaluated by comparing cells infected with GFPexpressing bacteria either with uninfected cells or cells infected with wild-type strains. The fluorescence ratio of infected cells increased during the $72 \mathrm{~h}$ period of infection in A549 and RAW cells (Fig. 3 a). The increasing GFP fluorescence observed over time, visualized as a displacement of the GFP-positive population to the right in the histograms, was consistent with the increasing numbers of intracellular bacteria (Fig. $3 \mathrm{~b}$ ).

\section{Phagosomal characteristics of $M$. abscessus strains in epithelial cells and macrophages}

Ultrastructural analyses and phagosome acidification studies were carried out to characterize phagosomes containing $M$. abscessus as well as host cell-lysosomal system interaction. After $24 \mathrm{~h}$ of infection, M. abscessus ATCC 19977 and M. abscessus CRM0019 were localized inside vacuoles in A549 cells and macrophages (Fig. 4). Representative TEM pictures show the characteristics of each strain, either in A549 or RAW cells. A549 phagosomes containing the clinical strain showed their membrane closely apposed to the mycobacterial cell surface, characteristic for R strains (Fig. 4 a). In RAW cells however, CRM0019 was also located in single phagosomes, but the phagosomal membrane was separated from the bacteria cell wall (Fig. 4 b). For the reference strain ATCC 19977, phagosomes showed a "loose" apposed membrane in both cell types (Fig. 4 c, d), characteristic of $\mathrm{S}$ variant strains. Moreover, most of the phagosomes here contained several bacteria. 


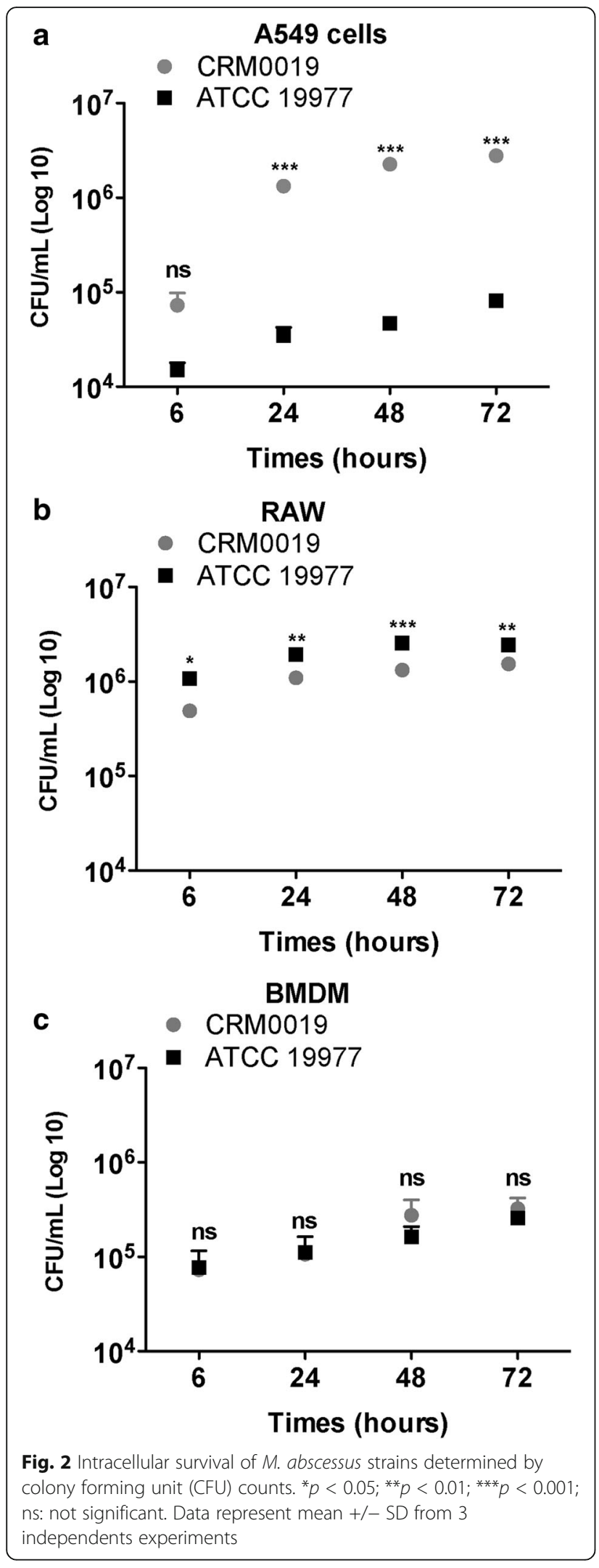

Phagosome maturation was evaluated in infected A549 and RAW cells previously loaded with the lysosomal marker LysoTracker Red. M. smegmatis $\mathrm{mc}^{2} 155$ was used in parallel as a control mycobacterium that allows lysosome fusion [60,65]. Live cell images were taken to follow mycobacterium phagosome acidification in LysoTracker Red pre-loaded A549 cells (Fig. 5). M. smegmatis phagosomes were much more acidified than $M$. abscessus phagosomes (Fig. 5 a, b). The sequence of images of M. abscessus phagosomes (Fig. 5 a) showed bacteria-GFP surrounded by LysoTracker Red-positive vesicles without a clear colocalization of phagosomes and mycobacteria. Similar results were observed for CRM0019 after $48 \mathrm{~h}$ infection in A549 cells, in which bacteria showed slight colocalization with acidic vesicles (see Additional file 4). With M. smegmatis there was evident colocalization of the mycobacteria (Fig. 5 b), and LysoTracker Red was observed in some recorded phagosomes, particularly in the first hours. Square regions of the multidimensional images (in yellow) were selected to measure LysoTracker Red intensity associated with the bacteria (Fig. 5 c). The mean LysoTracker Red fluorescence intensity in regions where mycobacteria were located was retrieved in arbitrary units and plotted in relation to the acquisition time points (in hours). $M$. abscessus ATCC 19977 phagosomes in A549 cells showed lower LysoTracker Red fluorescence intensity compared to the intensity produced by $M$. smegmatis infection (Fig. 5 c). To closely follow phagosomal maturation, A549 and RAW cells infected with the two $M$. abscessus strains were simultaneously immunolabeled with LAMP-1 and cathepsin D. Z-stack images of $M$. abscessus-infected A549 and RAW cells showed the colocalization of cathepsin D and LAMP-1 in the CRM0019 phagosomes (Fig. 6 a, b) as well as in the ATCC 19977 phagosomes (see Additional file 5). Almost $80 \%$ of the vacuoles containing $M$. abscessus ATCC 19977 were positive for both lysosomal markers, in either A549 or RAW cells (Fig. 6 c). However, for the clinical strain CRM0019 only $30 \%$ of the vacuoles were positive for LAMP-1 and cathepsin D in A549 cells. A different result was obtained with RAW cells, in which the maturation of $M$. abscessus CRM0019 phagosomes was similar to that observed for M. abscessus ATCC 19977, where there was almost $80 \%$ lysosomal protein colocalization.

\section{Reinfection of $M$. abscessus strains obtained from macrophages}

Because of the evidence that mycobacteria become more infective after the first intracellular infection [61, 62], we evaluated whether this holds for $M$. abscessus obtained from macrophages. The aforementioned results showed that $M$. abscessus were highly internalized by 

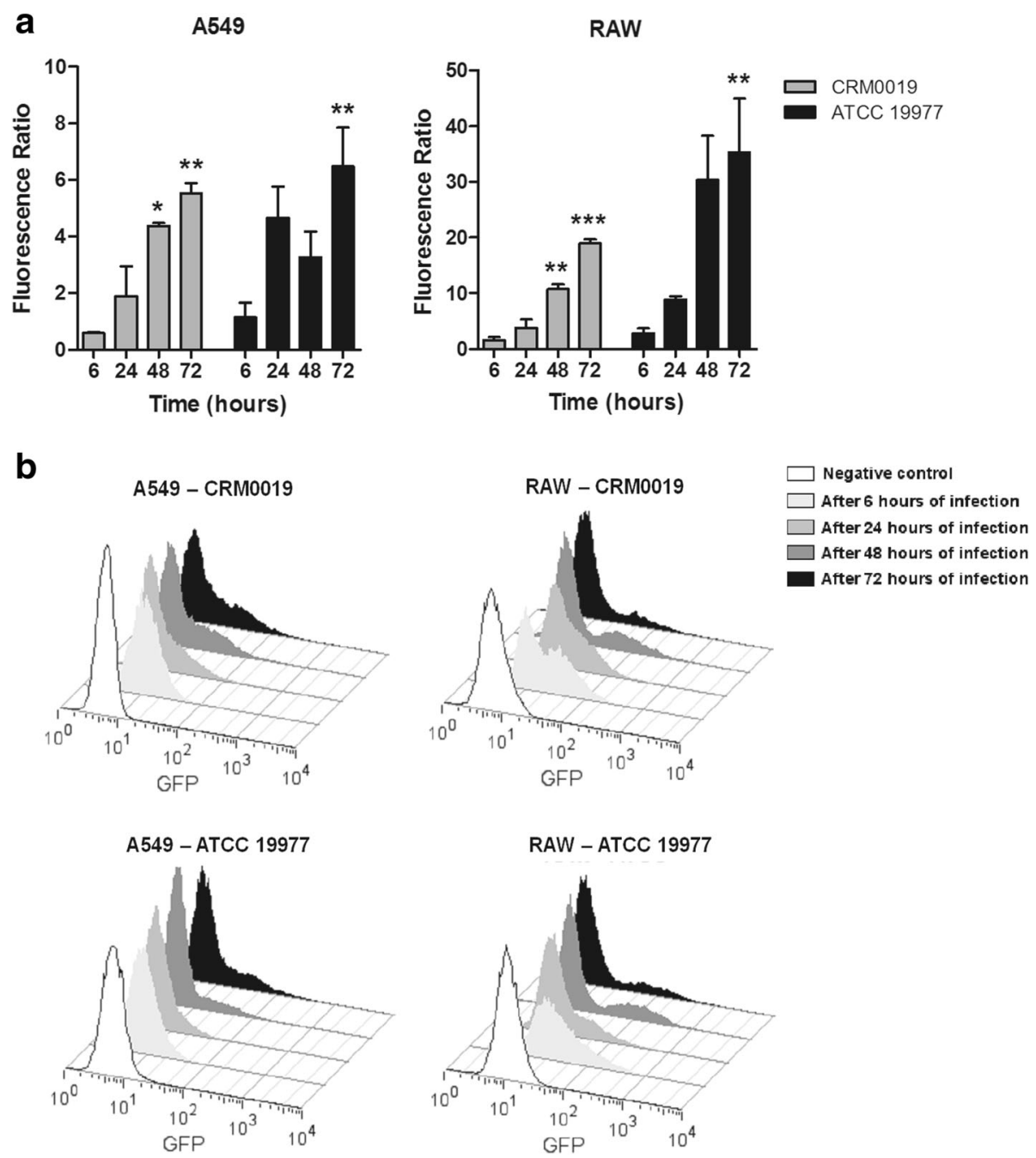

Fig. 3 Intracellular growth of M. abscessus strains by flow cytometry. Internalization of strain CRM0019 or ATCC 19977 in epithelial (A549) and macrophage (RAW) cell lines was detected by flow cytometry after 6, 24, 48 and $72 \mathrm{~h}$ of infection. Intracellular growth was evaluated by calculating fluorescence ratio (a) or with histograms of GFP fluorescence (b). Cells infected with wild-type bacteria and uninfected cells were used as negative controls for GFP fluorescence. Statistical differences were calculated between $6 \mathrm{~h}$, the first period of infection, and 24 , and $72 \mathrm{~h}$ of infection. ${ }^{*} p<0.05$ ${ }^{* *} p<0.01{ }^{* *} p<0.001$. Data represent mean $+/-$ SD from 3 independents experiments

macrophages and ended up in a mature lysosomal compartment without, however, evidence of intracellular death (Figs. 2 and 6). Mycobacteria obtained from BMDM previously infected for $24 \mathrm{~h}$ were used in reinfection assays of A549 cells or new macrophages (RAW and BMDM) (Fig. 7). The clinical strain showed increased growth in A549 cells compared to ATCC 19977 (Fig. 7), in which higher CFU counts were obtained after 48 and $72 \mathrm{~h}$ (Fig. 7 a). In RAW cells, this was observed only after $72 \mathrm{~h}$ (Fig. $7 \mathrm{~b}$ ); in the case of BMDM, the number of colonies obtained with CRM0019 was slightly higher compared to the reference strain (Fig. 7 c). CRM0019 showed a higher growth rate in A549 cells compared to the reference strain, mainly after 48 and $72 \mathrm{~h}$ (see Additional file 6), with a nearly 10-fold increase. For both macrophage lines, the results were similar to those observed in the first infection, except for RAW cells infected with CRM0019 at $72 \mathrm{~h}$ (see Additional file 3). Mycobacterial growth rate was also determined for M. smegmatis, which showed no colonies after reinfection of all cell types (data not shown).

\section{Discussion}

M. abscessus subsp. massiliense CRM0019 survives in macrophages and also subverts the immune response in vivo, which may contribute to its increased persistence [32]. Besides the ability to produce biofilms, limiting the efficacy of treatment, intracellular growth may also contribute to the successful survival of M. abscessus. In culture this bacteria exhibits two different colony 

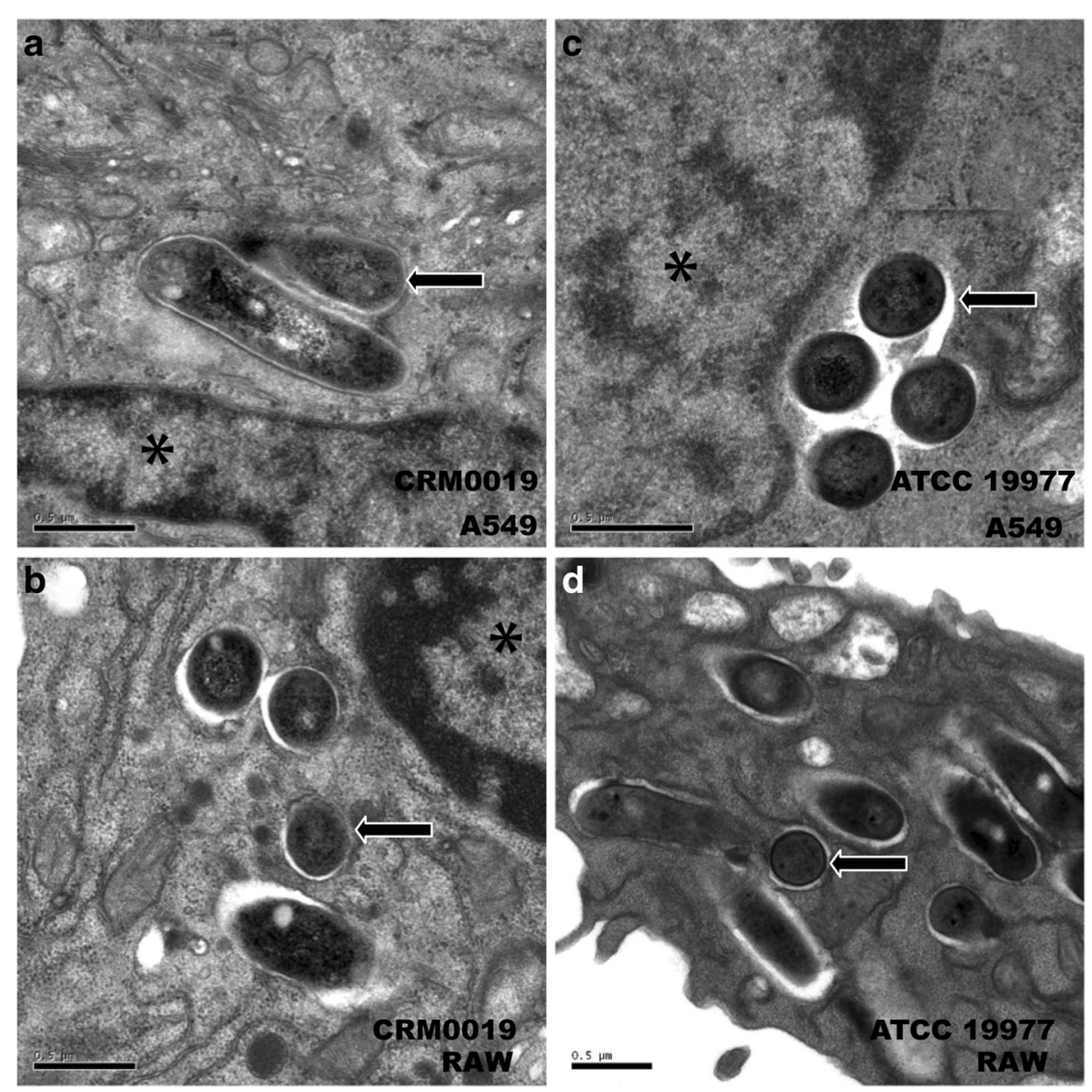

Fig. 4 Ultrastructural characterization of M. abscessus phagosomes after $24 \mathrm{~h}$ of infection. a, b M. abscessus CRM019 in A549 (a) or RAW (b) cells; (c, d) M. abscessus ATCC 19977 in A549 (c) or RAW (d) cells. Asterisks: host cell nuclei; arrow: intravacuolar bacteria; Bar: 0.5 m

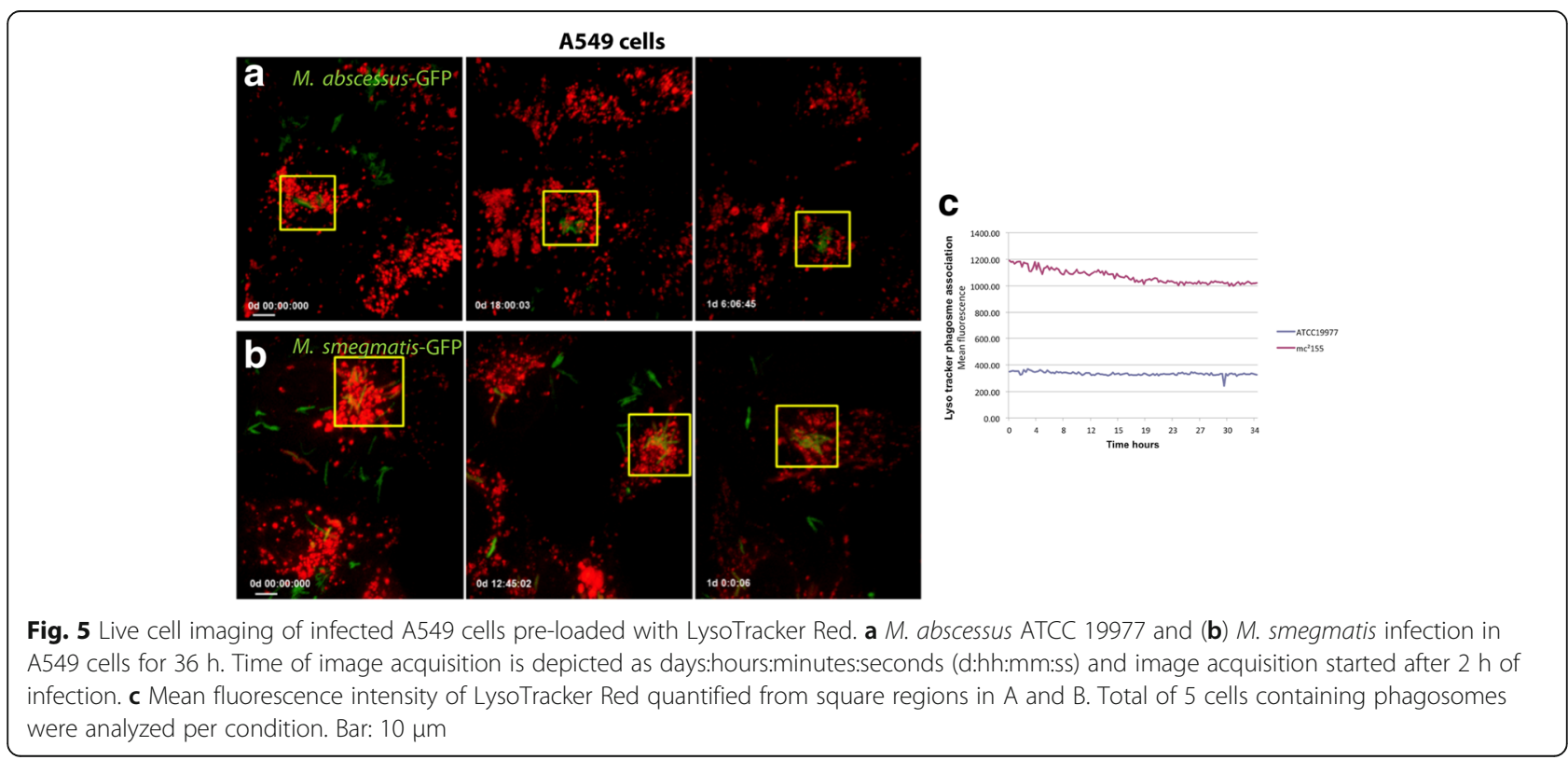




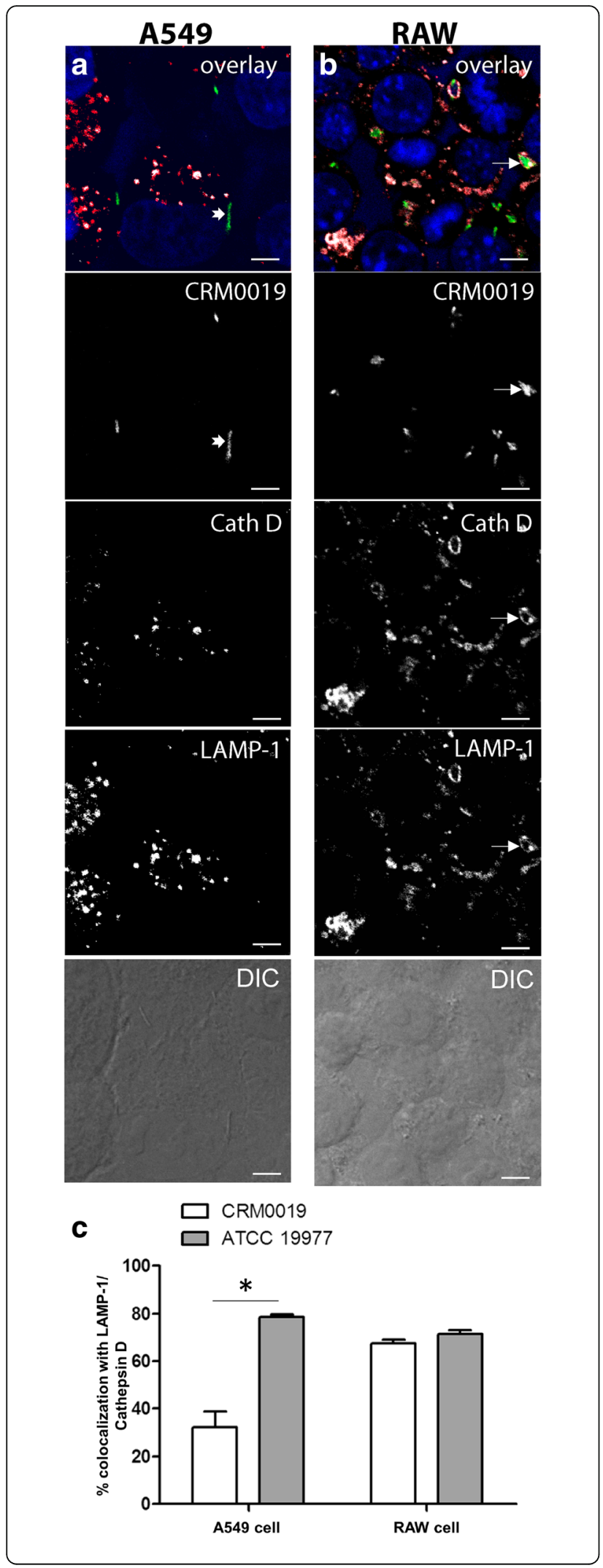

Fig. 6 Colocalization of lysosomal proteins in M. abscessus CRM0019 phagosomes. a-f Z-stack images were obtained from A549 (a) and RAW (b) cells infected with M. abscessus CRM0019 for $24 \mathrm{~h}$. $\mathbf{a}$ and $\mathbf{b}$ : Colocalization of mycobacteria-GFP, LAMP-1 and Cathepsin D, followed by the respective separated channels of CRM0019-GFP, Cathepsin D, LAMP-1 and transmitted light (DIC). c Quantification of M. abscessus CRM0019 and M. abscessus ATCC 19977 phagosomes simultaneously positive for LAMP-1 and cathepsin D in A549 and RAW cells. ${ }^{*} P<0.05$. 200 phagosomes were counted per condition. Bar: $10 \mu \mathrm{m}$

morphologies referred to as rough (R) and smooth (S) morphotypes [21]. Despite the R morphotype being considered more virulent, $\mathrm{S}$ variants have been identified as the dominant morphotype obtained from CF patients [23]. Likewise, CRM0019 obtained during an epidemic of postsurgical infections, displays an S morphotype ("personal communication" by Dr. Rafael Duarte), and is characterized by an aggressive and invasive behavior in vivo [30].

For several decades, observations from in vivo histological samples of patients or animal models have shown that macrophages are the predominant host cells for mycobacteria. However, bacilli may be released from macrophages and infect cells other than macrophages thus establishing a stable or chronic infection. A recent study using a human ex vivo lung model showed that besides immune cells, Type II pneumocytes were also infected with M. tuberculosis, M. avium and M. abscessus [53]. For the isolate CRM0019 we know from previous studies that this strain is highly virulent in vitro and causes progressive lung infections in mice [32].

Based on these observations we investigated the intracellular survival of the outbreak strain $M$. abscessus CRM0019, focusing on its interaction with the primary host defense system - lysosomal digestion, and its reinfection capability.

\section{Uptake of M. abscessus CRM0019 in A549 cells and macrophages}

There is considerable evidence towards the role of epithelial cells as a replicative niche for Mycobacterium survival $[47-52,54]$. Herein, we showed similar internalization rates for the clinical strain $M$. abscessus CRM0019 as for the reference strain ATCC 19977 in A549 cells. As expected, both strains were internalized by macrophages, and the survival of $M$. abscessus was in line with previously published data $[16,35,66]$. It has been shown that $\mathrm{S}$ and $\mathrm{R}$ mycobacteria morphotypes have distinct uptake efficacies in macrophages, most likely due to the intrinsic clumping behavior of $\mathrm{R}$ strains [35]. Despite our extensive procedures to obtain single bacteria preparations, we also noticed a higher clumping tendency of the clinical strain, which is atypical for $\mathrm{S}$ 


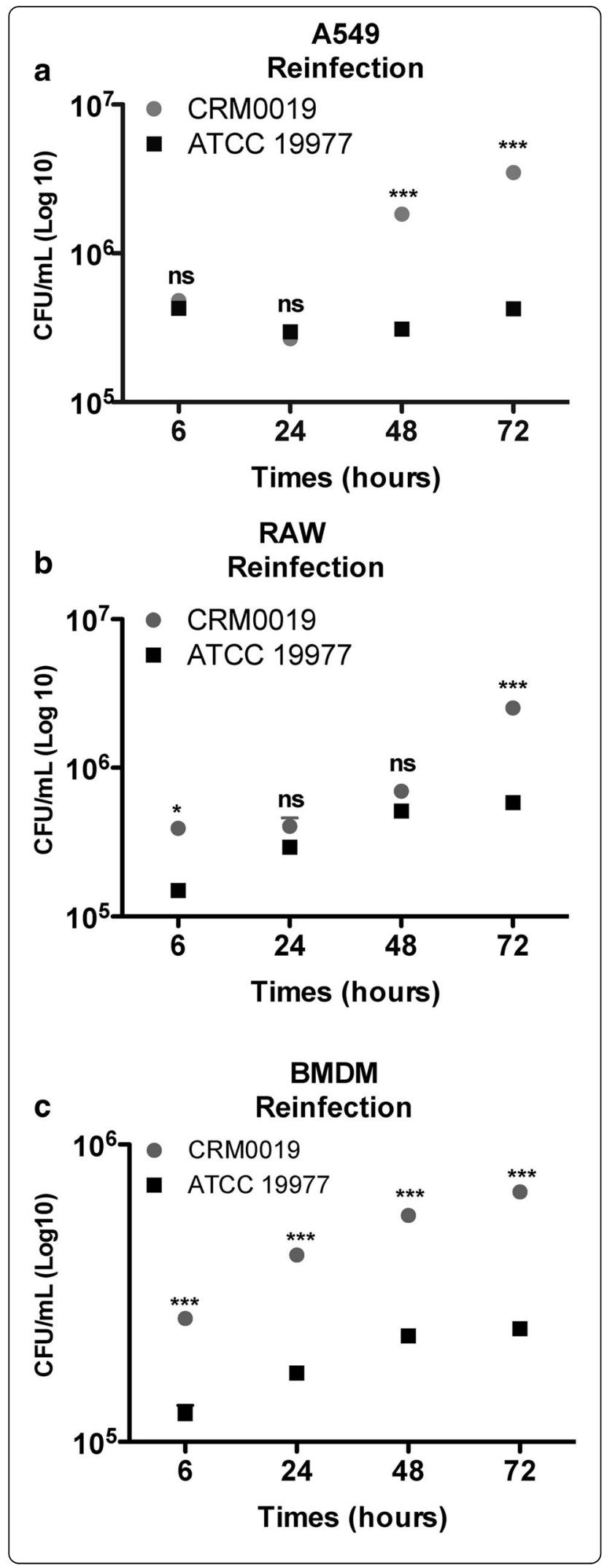

Fig. 7 Intracellular survival of M. abscessus CRM0019 and M. abscessus ATCC 19977 after cell-reinfection. a A549, b RAW and c BMDM were infected with both strains, previously obtained from BMDM. In parallel, intracellular growth was determined by CFU counts. Data represent mean \pm SD from 3 independent experiments. ${ }^{*} p<0.05 ;{ }^{* * *} p<0.001$; ns: not significant

morphotypes. Even so, this did not interfere with the uptake efficacy of CRM0019, either in A549 or RAW cells.

It is well known that the respiratory epithelium plays an important role in host innate immune responses to bacterial pathogens, through binding of the bacteria to TLR (toll like receptors). M. abscessus variant lacking GPL trigger immune responses in A549 cells through TLR, contrasting to the $\mathrm{S}$ variant that is not recognized by TLR2 [33]. Thus, we cannot exclude that CRM0019 can subvert innate immune responses triggered by TLR binding. Such a strategy should therefore be further investigated for M. abscessus CRM0019 strain.

Intracellular survival and intraphagosomal characteristics of $M$. abscessus CRM0019 strain

In contrast to the similar internalization rate of CRM0019 and ATCC 19977 in A549 cells, the intracellular survival of CRM0019 was higher than the reference strain as evidenced by CFU counts and flow cytometry data. As amikacin was maintained during the entire experiment, we believe that extracellular growth is quite unlikely to contribute to the increased CFU number, contrasting to what we observed in infected cultures without amikacin (see Additional file 2). Such higher survival of CRM0019 was unexpected and indeed more correlated to $\mathrm{R}$ variant behavior [16]. This is contradictory since the CRM0019 strain has S morphotype upon isolation.

It is possible that the low CFU number obtained from ATCC 19977 infection in A549 cells is due to a killing activity against this strain. Since ATCC 19977 was isolated in 1953, we cannot exclude a possible attenuation after several passages in a laboratory setting. Another reference strain, M. massiliense CIP 108297 - isolated in 2004 from the sputum of a patient with pneumonia also showed lower survival capability compared to the clinical isolate CRM0019 [32]. Nevertheless we believe that the difference between ATCC 19997 and CRM0019 survival might be related to the clinical significance of CRM0019 rather than only to the attenuation of the reference strain. Our hypothesis is supported by the results we obtained with another clinical strain $(M$. abscessus subsp. abscessus), recently isolated from CF patients, which showed higher survival in A549 cells, suggesting therefore that wild strains share the potential to cause disease. 
Epithelial cells may function as a protective niche for $M$. abscessus survival, and there is existing evidence to support this hypothesis. The first piece of evidence is from recent transcriptional data showing upregulation of genes in Type II epithelial cells related to the active proliferation of $M$. tuberculosis [52]. Moreover, M. abscessus isolated from human endophthalmitis cases exhibited increased intracellular survival in endothelial cells and higher levels of nitric oxide production compared to $M$. smegmatis or M. tuberculosis [36]. Thus, the evidence of higher proliferation of pathogenic mycobacteria in cells other than macrophages supports our results, in which CRM0019 shows a more infective profile than the reference strain in A549 cells.

The success of pathogenic mycobacteria depends on their ability to survive inside vacuoles and to prevent phagosome maturation [67-69] and for CRM0019 strain this may be no different. Our findings show that in both RAW or BMDM macrophages clinical and reference strains of $M$. abscessus were localized in acidified compartments while maintaining proliferative capacity. This is in contrast to the results obtained with $M$. smegmatis, in which the bacilli were, as expected, eliminated in macrophages. Regardless of the acidic nature of $M$. abscessus phagosomes, no bacterial death was observed up to $72 \mathrm{~h}$ of infection, noted by the constant number of viable colonies (CFU). Such behavior is in line with other findings confirming intracellular survival of $M$. abscessus in macrophages $[16,35,66,70]$. Indeed, the successful survival of pathogenic mycobacteria in the potentially hostile environment of macrophages has been extensively reported for pathogenic mycobacterium like $M$. tuberculosis, M. bovis or $M$. bovis BCG $[39,69,71-73]$. Such persistent behavior results in a sustained intracellular survival for several days $[71,73]$, being also facilitated by the emergence of multidrug-resistant strains [74].

Macrophages represent the first line of cellular defense against pathogens, and it is well known that $M$. tuberculosis is able to subvert the defense machinery of these cells, which is characterized by production of toxic oxygen and nitrogen radicals, as well as phagosome maturation. Lysosome fusion is the end point to degrade internalized microbes. Intracellular survival of $M$. abscessus CRM0019 not only in macrophages but also in A549 cells, suggests that this strain has additional strategies to counteract the intracellular defense machinery. Our results showed that one difference is the acquisition of lysosomal proteins by CRM0019, which was not as significant in RAW as in A549 cells.

Ultrastructural analysis of $M$. abscessus CRM0019 and ATCC 19977-containing phagosomes showed that in RAW macrophages, both bacterial strains reside within phagosomes, usually consisting of a single bacterium. Such a characteristic is also supported by recent work from Roux and collaborators [35]. In their report, the $S$ variant exhibited a thick GPL-rich cell wall, apposed to the phagosomal membrane, which is in line with our findings. Nevertheless, in A549 cells, the phagosomal membrane was tightly adherent to the CRM0019 cell wall, a characteristic usually observed in $\mathrm{R}$ variants [16, 35]. Conversely, the ATCC 19977 strain had the phagosomal membrane loosely associated to its cell wall, a finding that supports characteristics of S variant, previously described by other groups [16, 35]. Observations by the de Chastellier group suggested that pathogenic mycobacteria have a close apposition of the phagosome membrane, and that such an arrangement was crucial to prevent phagosome maturation [75]. CRM0019 also showed a close membrane apposition to the phagosome in A549 cells, explaining the prevention in acquisition of lysosomal proteins in the phagosomes. Unexpectedly, these characteristics could not be observed in macrophages.

It has been widely described that $S$ and $R$ variants have different behavior with regard to their in vivo interactions as well as with eukaryotic cells. $M$. abscessus bacteria with $S$ phenotype avoid immune responses from epithelial cells, contrasting to bacteria with $\mathrm{R}$ phenotype [33]. The $\mathrm{S}$ variant shows indeed an attenuated ability to infect murine hosts and to persist in human monocytes [16]. From our results, the infection of CRM0019 in A549 cells had some peculiar characteristics generally observed for the $\mathrm{R}$ morphotype, for instance the higher survival. Nonetheless, this strain showed $\mathrm{S}$ morphotype upon isolation. A spontaneous transition from $\mathrm{S}$ to an $\mathrm{R}$ phenotype by $M$. abscessus CRM0019 cannot be excluded, since it could contribute to the establishment of an aggressive and persistent infection. Some groups have already shown the switch between $S$ to $R$ variants in CF strains $[25,76]$.

\section{Reinfection of $M$. abscessus strains obtained from macrophages}

Following respiratory infection, alveolar macrophages are essential to eliminate inhaled microbes. Nevertheless, pathogens can overcome this primary immune defense and spread the infection, which seems to be the case for M. abscessus infection. Infected macrophages are also able to migrate through epithelial and endothelial barriers, which may contribute to extrapulmonary infections [77]. Within this scenario, we examined the infective competence of $M$. abscessus after first infection in macrophages, in which the bacilli were in a stationary growth phase and harbored within mature phagosomes (Figs. 2 and 6). Although second infection occurred to a lesser degree when compared to initial infection, only the clinical strain CRM0019 grew in A549 cells and macrophages in a second infection, which may explain the long persistence of the observed in vivo infection [32]. Evidence suggests that intracellular passage through epithelial cells changes the 
mycobacterial phenotype to a more pathogenic one during infection of macrophages, epithelial or endothelial cells [61, 77, 78]. In our study, mycobacteria obtained from macrophages were not more infective but were still able to survive in either macrophages or alveolar epithelial cells. Whether the S morphotype of CRM0019 strain spontaneously switches to an $\mathrm{R}$ morphotype after a first infection in macrophages is an open question that should be further investigated. We believe that the release of bacteria by macrophages may contribute to subsequent infections and their persistence in the host. Recently, it was elegantly shown in a zebrafish model that macrophages harboring $M$. abscessus undergo apoptosis and release bacteria into the extracellular medium, which can be pathogenic and induce lethal infections [79]. Future work addressing genomic and transcriptomic changes in $M$. abscessus, obtained from a first infection in macrophages or in alveolar epithelial cells, would help to understand the adaptation of this bacteria to the intracellular environment.

\section{Conclusion}

In conclusion, this work demonstrated that $M$. abscessus CRM0019 survives in alveolar epithelial cells mainly due to the inhibition of phagosome maturation. Macrophages containing these bacteria are not able to kill them despite the mature characteristics of their phagosomes. Finally, $M$. abscessus CRM0019 recovered from macrophages are able to establish a new intracellular infection, which may explain the aggressive profile of this strain.

\section{Additional files}

Additional file 1: Cell viability after M. abscessus infection. (A) A549, (B) RAW and (C) BMDM were infected for 6-72 $\mathrm{h}$ with M. abscessus CRM0019. Infection did not induce evident cytotoxicity during this time. Data represent mean \pm SD from 2 independent experiments. No statistical difference was observed for each time point. (TIFF $225 \mathrm{~kb}$ )

Additional file 2: Intracellular survival of $M$. abscessus subsp. abscessus smooth (MABS), isolated from CF patients. A549 cells infected with $M$. abscessus were incubated with or without amikacin, for 6-72 h. Significant differences between treated and untreated are indicated at each time point. Data represent mean \pm SD from 2 independent experiments. ${ }^{*} p<0.05,{ }^{* * *} p<0.001$. (TIFF $148 \mathrm{~kb}$ )

Additional file 3: Growth rate of $M$. abscessus strains. The CFU obtained in Fig. 2c was used to calculate the growth rate of M. abscessus CRM0019 or M. abscessus ATCC 19977 in (A) A549, (B) RAW or (C) BMDM cells. $\mathrm{Tf}=24,48$ or $72 \mathrm{~h}$ and $\mathrm{Ti}=6 \mathrm{~h}$. Data represent mean $\pm \mathrm{SD}$ from 3 independent experiments. ${ }^{* *} p<0.001$; ns: not significant. (TIFF $314 \mathrm{~kb}$ )

Additional file 4: $M$. abscessus CRM0019 phagosome acidification in A549 cells after $48 \mathrm{~h}$ infection. (A) overlay of CRM0019-GFP and Lyso tracker red; (B) CRM0019; (C) Lyso tracker red. Arrow: intracellular bacteria loosely associated with acidic vesicles. Bar: $10 \mu \mathrm{m}$. (TIFF $14938 \mathrm{~kb}$ )

Additional file 5: Colocalization of lysosomal proteins in M. abscessus ATCC 19977 phagosomes. (A-F) Z-stack images were obtained from RAW infected for $24 \mathrm{~h}$. (A) Mycobacteria-GFP; (B) LAMP-1: (C) Cathepsin D; (D) Colocalization of A, B and C; (E) Transmitted light; (F) Colocalization of GFP, LAMP-1 and DAPI. Bar: $10 \mu \mathrm{m}$. (TIFF $27030 \mathrm{~kb}$ )
Additional file 6: Growth rate of $M$ abscessus CRM0019 and $M$ abscessus ATCC 19977 after reinfection. (A) A549, (B) RAW or (C) BMDM cells. Growth rate was determined by the ratio $\mathrm{Tf} / \mathrm{Ti}$, in which $\mathrm{Tf}=24,48$ or $72 \mathrm{~h}$ and $\mathrm{Ti}=6 \mathrm{~h}$. ${ }^{* * *} \mathrm{p}<0.001$; ns: not significant. (TIFF $365 \mathrm{~kb}$ )

\section{Abbreviations \\ AEC: Alveolar epithelial cell; BMDM: Bone marrow-derived macrophages; CFU: Colony-forming units; GFP: Green fluorescent protein; \\ GPLs: Glycopeptidolipids; MTT: Methyl-thiazolyl tetrazolium; NTM: Nontuberculous mycobacterium; R: Rough; RGM: Rapid-growing mycobacteria; S: Smooth; TLR: Toll like receptors}

\section{Acknowledgments \\ We acknowledge Prof. Edna Freymuller and the technicians of the Electron Microscope Service of UNIFESP for helping with EM images. Dr. A. Leyva helped with English editing of the manuscript. Dr. Sarah Gordon for the proof reading of the revised version. We also acknowledge the help of Ms. Adriely Goes Conceição with plating of colonies and Ms. Jana Westhues for A549 cell culture.}

\section{Funding}

GMR, CKM and CSCW received grants from São Paulo Research Foundation (FAPESP) (2012/04913-8, 2013/16018-6 and 2009/14665-9).

\section{Availability of data and materials}

All data generated or analyzed during this study are included in this published article and raw data sets are available from the corresponding author on reasonable request.

\section{Author's contributions}

CSCW, GMR, SCL conceived and designed the experiments; GMR and CSCW performed the experiments. CKM transformed the bacteria strains. FR designed and helped with live cell experiments. GMR and DT performed and analyzed the cytometry data. RSD contributed with phenotypic and genotypic characterizations of CRM0019 isolate and paper preparation. RAM contributed to confocal microscopy data acquisition and analysis and revision of the manuscript. RSD, RAM, SCL contributed reagents/materials/ analysis tools. CSCW was the major contributor in writing the manuscript. All authors read and approved the final manuscript.

\section{Ethics approval and consent to participate}

All animal procedures were conducted under Brazilian National Committee on Ethics in Research (CONEP). The present study was approved by CEP/ UNIFESP (Comitê de Ética em Pesquisa da Universidade Federal de São Paulo/Hospital São Paulo) under the protocol number 0856/07.

Consent for publication

Not applicable.

\section{Competing interests}

The authors declare that they have no competing interests.

\section{Publisher's Note}

Springer Nature remains neutral with regard to jurisdictional claims in published maps and institutional affiliations.

\section{Author details}

${ }^{1}$ Departamento de Microbiologia, Imunologia e Parasitologia, Escola Paulista de Medicina, Universidade Federal de São Paulo, São Paulo, SP, Brazil. ${ }^{2}$ Laboratoire Entrée muqueuse du VIH et Immunité muqueuse, Department Infection, Immunité et Inflammation, Institut Cochin, Paris, France. ${ }^{3}$ Laboratório de Micobactérias, Instituto de Microbiologia Professor Paulo de Góes, Cidade Universitária, Rio de Janeiro, Brazil. ${ }^{4}$ Department of Drug Delivery, Helmholtz Institute for Pharmaceutical Research Saarland (HIPS), Helmholtz Centre for Infection Research (HZI), Saarbrücken, Germany. 
Received: 28 March 2017 Accepted: 5 September 2017

\section{Published online: 13 September 2017}

\section{References}

1. Catherinot $E$, Gaillard $J \mathrm{~L}$, Couderc $\amalg$. Nontuberculous mycobacterial infections. Rev Prat. 2011;61(4):461-70.

2. Griffith DE, Girard WM, Wallace RJ Jr. Clinical features of pulmonary disease caused by rapidly growing mycobacteria. An analysis of 154 patients. Am Rev Respir Dis. 1993;147(5):1271-8.

3. Cardoso AM, Martins de Sousa E, Viana-Niero C, Bonfim de Bortoli F, Pereira das Neves ZC, Leao SC, Junqueira-Kipnis AP, Kipnis A. Emergence of nosocomial Mycobacterium massiliense infection in Goias, Brazil. Microbes Infect. 2008;10(14-15):1552-7.

4. Cheng A, Liu YC, Chen ML, Hung CC, Tsai YT, Sheng WH, Liao CH, Hsueh PR, Chen YC, Chang SC. Extrapulmonary infections caused by a dominant strain of Mycobacterium massiliense (Mycobacterium abscessus subspecies bolletii). Clin Microbiol Infect. 2013;19(10):E473-82

5. Furuya EY, Paez A, Srinivasan A, Cooksey R, Augenbraun M, Baron M, Brudney K, Della-Latta P, Estivariz C, Fischer S, et al. Outbreak of Mycobacterium abscessus wound infections among "lipotourists" from the United States who underwent abdominoplasty in the Dominican Republic Clin Infect Dis. 2008:46(8):1181-8.

6. Olivier KN, Weber DJ, Wallace RJ Jr, Faiz AR, Lee JH, Zhang Y, Brown-Elliot BA, Handler A, Wilson RW, Schechter MS, et al. Nontuberculous mycobacteria. I: multicenter prevalence study in cystic fibrosis. Am J Respir Crit Care Med. 2003;167(6):828-34.

7. Roux AL, Catherinot E, Ripoll F, Soismier N, Macheras E, Ravilly S, Bellis G, Vibet MA, Le Roux E, Lemonnier L, et al. Multicenter study of prevalence of nontuberculous mycobacteria in patients with cystic fibrosis in france. J Clin Microbiol. 2009:47(12):4124-8.

8. Floto RA, Olivier KN, Saiman L, Daley CL, Herrmann JL, Nick JA, Noone PG, Bilton D, Corris P, Gibson RL, et al. US Cystic Fibrosis Foundation and European Cystic Fibrosis Society consensus recommendations for the management of non-tuberculous mycobacteria in individuals with cystic fibrosis. Thorax. 2016;71(Suppl 1):i1-22.

9. Al-Sulami AA, Al-Taee AM, Wida'a QH. Isolation and identification of Mycobacterium avium complex and other nontuberculosis mycobacteria from drinking-water in Basra governorate, Iraq. East Mediterr Health J. 2012; 18(3):274-8

10. Thomson R, Tolson C, Carter R, Coulter C, Huygens F, Hargreaves M. Isolation of nontuberculous mycobacteria (NTM) from household water and shower aerosols in patients with pulmonary disease caused by NTM. J Clin Microbiol. 2013;51(9):3006-11.

11. Thomson R, Tolson C, Sidjabat H, Huygens F, Hargreaves M. Mycobacterium abscessus isolated from municipal water - a potential source of human infection. BMC Infect Dis. 2013;13:241.

12. Harris KA, Underwood A, Kenna DT, Brooks A, Kavaliunaite E, Kapatai G, Tewolde R, Aurora P, Dixon G. Whole-genome sequencing and epidemiological analysis do not provide evidence for cross-transmission of mycobacterium abscessus in a cohort of pediatric cystic fibrosis patients. Clin Infect Dis. 2015;60(7):1007-16.

13. Ripoll F, Deshayes C, Pasek S, Laval F, Beretti JL, Biet F, Risler IL, Daffe M, Etienne G, Gaillard JL, et al. Genomics of glycopeptidolipid biosynthesis in Mycobacterium abscessus and M. chelonae. BMC Genomics. 2007;8:114.

14. Lamrabet $\mathrm{O}$, Merhej $\mathrm{V}$, Pontarotti $\mathrm{P}$, Raoult D, Drancourt M. The genealogic tree of mycobacteria reveals a long-standing sympatric life into free-living protozoa. PLoS One. 2012;7(4):e34754

15. Ripoll F, Pasek S, Schenowitz C, Dossat C, Barbe V, Rottman M, Macheras E, Heym B, Herrmann JL, Daffe $M$, et al. Non mycobacterial virulence genes in the genome of the emerging pathogen Mycobacterium abscessus. PLoS One. 2009;4(6):e5660.

16. Byrd TF, Lyons CR. Preliminary characterization of a Mycobacterium abscessus mutant in human and murine models of infection. Infect Immun. 1999;67(9):4700-7.

17. Adekambi T, Reynaud-Gaubert M, Greub G, Gevaudan MJ, La Scola B, Raoult D, Drancourt M. Amoebal coculture of "Mycobacterium massiliense" sp. nov. from the sputum of a patient with hemoptoic pneumonia. J Clin Microbiol. 2004;42(12):5493-501.

18. Tortoli E, Kohl TA, Brown-Elliott BA, Trovato A, Leão SC, Garcia MJ, Vasireddy S, Turenne CY, Griffith DE, Philley JV, et al. Emended description of Mycobacterium abscessus, Mycobacterium abscessus subsp. abscessus and
Mycobacteriumabscessus subsp. bolletii and designation of Mycobacteriumabscessus subsp. massiliense comb. nov. Int J Syst Evol Microbiol. 2016;66(11):4471-9.

19. Leao SC, Tortoli E, Viana-Niero C, Ueki SY, Lima KV, Lopes ML, Yubero J, Menendez MC, Garcia MJ. Characterization of mycobacteria from a major Brazilian outbreak suggests that revision of the taxonomic status of members of the Mycobacterium chelonae-M. abscessus group is needed. J Clin Microbiol. 2009;47(9):2691-8.

20. Barrow WW, Ullom BP, Brennan PJ. Peptidoglycolipid nature of the superficial cell wall sheath of smooth-colony-forming mycobacteria. J Bacteriol. 1980;144(2):814-22.

21. Howard ST, Rhoades E, Recht J, Pang X, Alsup A, Kolter R, Lyons CR, Byrd TF. Spontaneous reversion of Mycobacterium abscessus from a smooth to a rough morphotype is associated with reduced expression of glycopeptidolipid and reacquisition of an invasive phenotype. Microbiology. 2006;152(Pt 6):1581-90.

22. Catherinot E, Clarissou J, Etienne G, Ripoll F, Emile JF, Daffe M, Perronne C, Soudais C, Gaillard $J$, Rottman M. Hypervirulence of a rough variant of the Mycobacterium abscessus type strain. Infect Immun. 2007;75(2):1055-8.

23. Ruger K, Hampel A, Billig S, Rucker N, Suerbaum S, Bange FC. Characterization of rough and smooth morphotypes of Mycobacterium abscessus isolates from clinical specimens. J Clin Microbiol. 2014;52(1):244-50,

24. Jonsson BE, Gilljam M, Lindblad A, Ridell M, Wold AE, Welinder-Olsson C. Molecular epidemiology of Mycobacterium abscessus, with focus on cystic fibrosis. J Clin Microbiol. 2007;45(5):1497-504.

25. Catherinot E, Roux AL, Macheras E, Hubert D, Matmar M, Dannhoffer L, Chinet $T$, Morand P, Poyart C, Heym B, et al. Acute respiratory failure involving an $R$ variant of Mycobacterium abscessus. J Clin Microbiol. 2009;47(1):271-4.

26. Sanguinetti M, Ardito F, Fiscarelli E, La Sorda M, D'Argenio P, Ricciotti G, Fadda G. Fatal pulmonary infection due to multidrug-resistant Mycobacterium abscessus in a patient with cystic fibrosis. J Clin Microbiol. 2001;39(2):816-9.

27. Preece CL, Perry A, Gray B, Kenna DT, Jones AL, Cummings SP, Robb A, Thomas MF, Brodlie M, O'Brien CJ, et al. A novel culture medium for isolation of rapidly-growing mycobacteria from the sputum of patients with cystic fibrosis. J Cyst Fibros. 2016;15(2):186-91.

28. Duarte RS, Lourenco MC, Fonseca Lde S, Leao SC, Amorim Ede L, Rocha IL, Coelho FS, Viana-Niero C, Gomes KM, da Silva MG, et al. Epidemic of postsurgical infections caused by Mycobacterium massiliense. J Clin Microbiol. 2009;47(7):2149-55.

29. Leao SC, Viana-Niero C, Matsumoto CK, Lima KV, Lopes ML, Palaci M, Hadad DJ, Vinhas S, Duarte RS, Lourenco MC, et al. Epidemic of surgical-site infections by a single clone of rapidly growing mycobacteria in Brazil. Future Microbiol. 2010;5(6):971-80.

30. Nunes Lde SBL, Ribeiro MO, Cardoso CM, de Paris F, De David SM, da Silva MG, Duarte RS, Barth AL. Outbreaks due to Mycobacterium abscessus subsp. bolletii in southern Brazil: persistence of a single clone from 2007 to 2011. J Med Microbiol. 2014;63(Pt 10):1288-93.

31. Lorena NS, Pitombo MB, Cortes PB, Maya MC, Silva MG, Carvalho AC, Coelho FS, Miyazaki NH, Marques EA, Chebabo A, et al. Mycobacterium massiliense BRA100 strain recovered from postsurgical infections: resistance to high concentrations of glutaraldehyde and alternative solutions for high level disinfection. Acta Cir Bras. 2010;25(5):455-9.

32. Shang S, Gibbs S, Henao-Tamayo M, Shanley CA, McDonnell G, Duarte RS, Ordway DJ, Jackson M. Increased virulence of an epidemic strain of Mycobacterium massiliense in mice. PLoS One. 2011;6(9):e24726.

33. Davidson LB, Nessar R, Kempaiah P, Perkins DJ, Byrd TF. Mycobacterium abscessus glycopeptidolipid prevents respiratory epithelial TLR2 signaling as measured by HbetaD2 gene expression and IL-8 release. PLoS One. 2011; 6(12):e29148.

34. Jonsson B, Ridell M, Wold AE. Phagocytosis and cytokine response to rough and smooth colony variants of Mycobacterium abscessus by human peripheral blood mononuclear cells. APMIS. 2013;121(1):45-55.

35. Anne-Laure Roux AV, A Bah, R Simeone, A Bernut, L Laencina, T Deramaudt, M Rottman, J-L Gaillard, L Majlessi, R Brosch, F Girard-Misguich, I Vergne, C de Chastellier, Laurent Kremer, and J-L Herrmann The distinct fate of smooth and rough Mycobacterium abscessus variants inside macrophages. Open Biology. 2016;6(11):1-12.

36. Garcia-Perez BE, Villagomez-Palatto DA, Castaneda-Sanchez JI, Coral-Vazquez RM, Ramirez-Sanchez I, Ordonez-Razo RM, Luna-Herrera J. Innate response of human endothelial cells infected with mycobacteria. Immunobiology. 2011;216(8):925-35. 
37. Lee HM, Yuk JM, Kim KH, Jang J, Kang G, Park JB, Son JW, Jo EK. Mycobacterium abscessus activates the NLRP3 inflammasome via Dectin-1Syk and p62/SQSTM1. Immunol Cell Biol. 2012;90(6):601-10.

38. Malcolm KC, Nichols EM, Caceres SM, Kret JE, Martiniano SL, Sagel SD, Chan ED, Caverly L, Solomon GM, Reynolds P, et al. Mycobacterium abscessus induces a limited pattern of neutrophil activation that promotes pathogen survival. PLoS One. 2013;8(2):e57402.

39. Russell DG, VanderVen BC, Lee W, Abramovitch RB, Kim MJ, Homolka S, Niemann S, Rohde KH. Mycobacterium tuberculosis wears what it eats. Cell Host Microbe. 2010;8(1):68-76.

40. Vergne I, Chua J, Lee HH, Lucas M, Belisle J, Deretic V. Mechanism of phagolysosome biogenesis block by viable Mycobacterium tuberculosis. Proc Natl Acad Sci U S A. 2005;102(11):4033-8.

41. Tufariello JM, Chan J, Flynn JL. Latent tuberculosis: mechanisms of host and bacillus that contribute to persistent infection. Lancet Infect Dis. 2003;3(9):578-90

42. Stewart GR, Robertson BD, Young DB. Tuberculosis: a problem with persistence. Nat Rev Microbiol. 2003;1(2):97-105.

43. Vandal OH, Pierini LM, Schnappinger D, Nathan CF, Ehrt S. A membrane protein preserves intrabacterial $\mathrm{pH}$ in intraphagosomal Mycobacterium tuberculosis. Nat Med. 2008;14(8):849-54.

44. Bouley DM, Ghori N, Mercer KL, Falkow S, Ramakrishnan L. Dynamic nature of host-pathogen interactions in Mycobacterium marinum granulomas. Infect Immun. 2001;69(12):7820-31.

45. Menendez MC, Garcia MJ, Navarro MC, Gonzalez-y-Merchand JA, RiveraGutierrez S, Garcia-Sanchez L, Cox RA. Characterization of an rRNA operon (rrnB) of Mycobacterium fortuitum and other mycobacterial species: implications for the classification of mycobacteria. J Bacteriol. 2002;184(4):1078-88.

46. Bals R, Hiemstra PS. Innate immunity in the lung: how epithelial cells fight against respiratory pathogens. Eur Respir J. 2004;23:327-33.

47. Hernandez-Pando R, Jeyanathan M, Mengistu G, Aguilar D, Orozco H, Harboe M, Rook GA, Bjune G. Persistence of DNA from Mycobacterium tuberculosis in superficially normal lung tissue during latent infection. Lancet. 2000;356(9248):2133-8.

48. Shepard CC. Phagocytosis by HeLa cells and their susceptibility to infection by human tubercle bacilli. Proc Soc Exp Biol Med. 1955;90(2):392-6.

49. Bermudez LE, Goodman J. Mycobacterium tuberculosis invades and replicates within type II alveolar cells. Infect Immun. 1996;64(4):1400-6.

50. Castro-Garza J, King CH, Swords WE, Quinn FD. Demonstration of spread by Mycobacterium tuberculosis bacilli in A549 epithelial cell monolayers. FEMS Microbiol Lett. 2002;212(2):145-9.

51. Garcia-Perez BE, Mondragon-Flores R, Luna-Herrera J. Internalization of Mycobacterium tuberculosis by macropinocytosis in non-phagocytic cells. Microb Pathog. 2003:35(2):49-55.

52. Ryndak MB, Singh KK, Peng Z, Laal S. Transcriptional profiling of Mycobacterium tuberculosis replicating in the human type II alveolar epithelial cell line, A549. Genom Data. 2015;5:112-4.

53. Ganbat D, Seehase S, Richter E, Vollmer E, Reiling N, Fellenberg K, Gaede Kl, Kugler C, Goldmann T. Mycobacteria infect different cell types in the human lung and cause species dependent cellular changes in infected cells. BMC Pulm Med. 2016;16:19.

54. Nardone LL, Andrews SB. Cell line A549 as a model of the type II pneumocyte. Phospholipid biosynthesis from native and organometallic precursors. Biochim Biophys Acta. 1979;573(2):276-95.

55. Foster KA, Oster CG, Mayer MM, Avery ML, Audus KL. Characterization of the A549 cell line as a type II pulmonary epithelial cell model for drug metabolism. Exp Cell Res. 1998;243(2):359-66.

56. Kallio A, Sepponen K, Hermand P, Denoel P, Godfroid F, Melin M. Role of Pht proteins in attachment of Streptococcus pneumoniae to respiratory epithelial cells. Infect Immun. 2014;82(4):1683-91.

57. Wang X, Tan J, Zoueva O, Zhao J, Ye Z, Hewlett I. Novel pandemic influenza A (H1N1) virus infection modulates apoptotic pathways that impact its replication in A549 cells. Microbes Infect. 2014;16(3):178-86.

58. Wang JH, Zhang K, Wang N, Qiu XM, Wang YB, He P. Involvement of phosphatidylinositol 3-Kinase/Akt signaling pathway in beta1 integrinmediated internalization of Staphylococcus aureus by alveolar epithelial cells. J Microbiol. 2013;51(5):644-50.

59. Chapeton-Montes JA, Plaza DF, Barrero CA, Patarroyo MA. Quantitative flow cytometric monitoring of invasion of epithelial cells by Mycobacterium tuberculosis. Front Biosci. 2008;13:650-6.
60. de Souza Carvalho C, Kasmapour B, Gronow A, Rohde M, Rabinovitch M Gutierrez MG. Internalization, phagolysosomal biogenesis and killing of mycobacteria in enucleated epithelial cells. Cell Microbiol. 2011;13(8):1234-49.

61. Kim SY, Sohn H, Choi GE, Cho SN, Oh T, Kim HJ, Whang J, Kim JS, Byun EH, Kim WS, et al. Conversion of Mycobacterium smegmatis to a pathogenic phenotype via passage of epithelial cells during macrophage infection. Med Microbiol Immunol. 2011;200(3):177-91.

62. Bakala N'Goma JC, Le Moigne V, Soismier N, Laencina L, Le Chevalier F, Roux AL, Poncin I, Serveau-Avesque C, Rottman M, Gaillard JL, et al. Mycobacterium abscessus phospholipase $C$ expression is induced during coculture within amoebae and enhances $M$. abscessus virulence in mice. Infect Immun. 2015;83(2):780-91.

63. Real F, Mortara RA, Rabinovitch M. Fusion between Leishmania amazonensis and Leishmania major parasitophorous vacuoles: live imaging of coinfected macrophages. PLoS Negl Trop Dis. 2010;4(12):e905.

64. Real F, Mortara RA. The diverse and dynamic nature of Leishmania parasitophorous vacuoles studied by multidimensional imaging. PLoS Negl Trop Dis. 2012;6(2):e1518.

65. Anes E, Peyron P, Staali L, Jordao L, Gutierrez MG, Kress H, Hagedorn M, Maridonneau-Parini I, Skinner MA, Wildeman AG, et al. Dynamic life and death interactions between Mycobacterium smegmatis and $\mathbf{J 7 7 4}$ macrophages. Cell Microbiol. 2006:8(6):939-60.

66. Oberley-Deegan RE, Lee YM, Morey GE, Cook DM, Chan ED, Crapo JD. The antioxidant mimetic, MnTE-2-PyP, reduces intracellular growth of Mycobacterium abscessus. Am J Respir Cell Mol Biol. 2009;41(2):170-8.

67. Yates RM, Hermetter A, Russell DG. The kinetics of phagosome maturation as a function of phagosome/lysosome fusion and acquisition of hydrolytic activity. Traffic. 2005;6(5):413-20.

68. Russell DG, Vanderven BC, Glennie S, Mwandumba H, Heyderman RS. The macrophage marches on its phagosome: dynamic assays of phagosome function. Nat Rev Immunol. 2009;9(8):594-600.

69. de Chastellier $C$. The many niches and strategies used by pathogenic mycobacteria for survival within host macrophages. Immunobiology. 2009;214(7):526-42.

70. Nessar R, Reyrat JM, Davidson LB, Byrd TF. Deletion of the $m m p L 4 b$ gene in the Mycobacterium abscessus glycopeptidolipid biosynthetic pathway results in loss of surface colonization capability, but enhanced ability to replicate in human macrophages and stimulate their innate immune response. Microbiology. 2011;157(Pt 4):1187-95.

71. Jordao L, Bleck CK, Mayorga L, Griffiths G, Anes E. On the killing of mycobacteria by macrophages. Cell Microbiol. 2008;10(2):529-48.

72. Podinovskaia M, Lee W, Caldwell S, Russell DG. Infection of macrophages with Mycobacterium tuberculosis induces global modifications to phagosomal function. Cell Microbiol. 2013;15(6):843-59.

73. Kalluru R, Fenaroli F, Westmoreland D, Ulanova L, Maleki A, Roos N, Paulsen Madsen M, Koster G, Egge-Jacobsen W, Wilson S, et al. Poly(lactide-coglycolide)-rifampicin nanoparticles efficiently clear Mycobacterium bovis BCG infection in macrophages and remain membrane-bound in phagolysosomes. J Cell Sci. 2013;126(Pt 14):3043-54.

74. Gandhi NR, Moll A, Sturm AW, Pawinski R, Govender T, Lalloo U, Zeller K, Andrews J, Friedland G. Extensively drug-resistant tuberculosis as a cause of death in patients co-infected with tuberculosis and HIV in a rural area of South Africa. Lancet. 2006;368(9547):1575-80.

75. de Chastellier C, Thilo L. Cholesterol depletion in Mycobacterium aviuminfected macrophages overcomes the block in phagosome maturation and leads to the reversible sequestration of viable mycobacteria in phagolysosome-derived autophagic vacuoles. Cell Microbiol. 2006;8(2):242-56.

76. Cullen AR, Cannon CL, Mark EJ, Colin AA. Mycobacterium abscessus infection in cystic fibrosis. Colonization or infection? Am J Respir Crit Care Med. 2000;161(2 Pt 1):641-5.

77. Bermudez LE, Sangari FJ, Kolonoski P, Petrofsky M, Goodman J. The efficiency of the translocation of Mycobacterium tuberculosis across a bilayer of epithelial and endothelial cells as a model of the alveolar wall is a consequence of transport within mononuclear phagocytes and invasion of alveolar epithelial cells. Infect Immun. 2002;70(1):140-6.

78. Sangari FJ, Goodman J, Bermudez LE. Mycobacterium avium enters intestinal epithelial cells through the apical membrane, but not by the basolateral surface, activates small GTPase Rho and, once within epithelial cells, expresses an invasive phenotype. Cell Microbiol. 2000;2(6):561-8.

79. Bernut A, Herrmann JL, Kissa K, Dubremetz JF, Gaillard JL, Lutfalla G, Kremer L. Mycobacterium abscessus cording prevents phagocytosis and promotes abscess formation. Proc Natl Acad Sci U S A. 2014;111(10):E943-52. 